Editorial

\title{
Decision-Making Under Uncertainty: African Migrants in the Spotlight
}

\author{
Didier Ruedin ${ }^{1,2}$ \\ ${ }^{1}$ Swiss Forum for Migration and Population Studies, University of Neuchâtel, 2000 Neuchâtel, Switzerland; \\ E-Mail: didier.ruedin@unine.ch \\ ${ }^{2}$ African Centre for Migration and Society, University of the Witwatersrand, Johannesburg, South Africa
}

Submitted: 27 January 2021 | Published: 25 March 2021

\begin{abstract}
This thematic issue examines questions of decision-making under limited (and contradictory) information, focusing on migration decisions. Migrants are far from a homogenous population, but they commonly use narratives as heuristics. We observe much agency among migrants to pursue migration plans, with migration decisions best understood as chains of multiple decisions rather than simple push-pull or two-step models.
\end{abstract}

\section{Keywords}

Africa; decision-making; immigration; narratives

\section{Issue}

This editorial is part of the issue "Decision-Making under Uncertainty: African Migrants in the Spotlight" edited by Didier Ruedin (University of the Witwatersrand, South Africa / University of Neuchâtel, Switzerland).

(C) 2021 by the author; licensee Cogitatio (Lisbon, Portugal). This editorial is licensed under a Creative Commons Attribution 4.0 International License (CC BY).

\section{Introduction}

In recent years, migration has become highly politicized in Western countries and many seek stricter forms of control (van der Brug, D'Amato, Berkhout, \& Ruedin, 2015). From the perspective of origin countries, however, we observe a desire to take part in the lifestyle and riches of the Global North (Auer, Römer, \& Tjaden, 2020; Smith, 2019). Two distinct literatures study why people migrate: On the one hand, migration studies have given us two-step models where an ambition to migrate is distinguished from the capability to do so (Carling \& Schewel, 2018; de Haas, 2011). Along with models highlighting social ties, two-step models help us understand why levels of migration are not higher given the extensive differences in economic and human development (Collier, 2013). On the other hand, contributions in economics and psychology have sharpened our understanding of rational decision-making (Kahneman, 2011): Often we make decisions in situations where perfect information is not available or costly, and individuals are probably bounded rational rather than purely self-regarding. Access to information also varies according to social and personality characteristics, which may include pre- vious migration experience and social networks (Baláž, Williams, \& Fifeková, 2016).

In the economics literature, two-step models are largely ignored, and the focus lies on wealth and income differences at the macro level, and human capital at the individual level. A key assumption continues to be that individuals and families optimize their situation within their possibilities, and often migration can improve the allocation of skills to the benefit of migrants and the economy (Constant \& Zimmermann, 2013). While providing a good basis to understand bounded rational decision-making, structural factors reducing the ability to migrate are typically not taken on board. By contrast, migration studies seem to assume perfectly informed decisions (albeit in two steps; see de Haas, 2011). As a result, many policymakers are puzzled why immigrants try to reach Europe despite seemingly impossible odds, or by contrast, why efforts to reduce unregulated migration seemingly fail to affect migration flows (Smith, 2019). Without communication between literatures, and without considering the perspective of origin countries and the individuals involved, however, we do not understand well why individuals decide to migrate, and we open the door for right-wing populism 
in destination countries politicizing against immigration that may encourage discrimination against immigrants and their descendants (Laurence, Schmid, \& Hewstone, 2018; Zschirnt \& Ruedin, 2016). At the UN-level, migration control is sought because uncontrolled migration often means exploitation (Ruedin \& Nesturi, 2018): Informed choices, effective policies, reduced risks for migrants on the move.

The objective of this thematic issue is to better understand how migrants decide whether to migrate and where to migrate to by considering the limited information available to them. All contributions in this thematic issue grapple with broader questions of decision-making. Examining migration decisions provides insights into mechanisms of decision-making that are otherwise too subtle to study. In the articles, we cannot find the homogenous group of 'migrants' as they are often perceived in destination countries: Great heterogeneity exists in ambitions to migrate, capabilities to do so, motives, routes, and reactions to changing circumstances 'on the way' - a 'way' which may never lead to the 'destination.' We do not observe naïve and gullible migrants ignorant of the risks and dangers of irregular migration, nor do we find masses of 'victims' tricked by fraudsters and smugglers. Instead, we observe individuals with aspirations, navigating a world characterized by limitations and boundaries. Information is patchy, but this has as much to do with the changing circumstances and opportunities-each risky to some extent. Under these circumstances, migrants show great flexibility to reach their goals, drawing on heuristics and narratives as is common in decision-making under limited information (Batista \& McKenzie, 2020; Smith, 2019). In fact, migration decisions are chains of multiple decisions that build one on another and can lead to unexpected turns (Crawley, Jones, McMahon, Duvell, \& Sigona, 2016).

\section{Understanding Migration Decisions}

The studies in this thematic issue contribute to understanding migration decisions in three areas: the decision to leave, decisions en route, and decisions as student migrants. Taken together, the contributions cover the entire journey and complexity of decision-making, and also include the retrospective view of migrants who have returned. First, several articles focus on ambitions to migrate and the initial decision to leave origin countries. Many individuals take considerable risks and take on debt in their endeavour to reach countries in the Global North. Narratives and images of economic opportunities, but also success stories from return migrants can trigger and amplify desires to migrate. Narratives play a strong role in shaping ambitions to migrate. These narratives help potential migrants to make sense of limited and contradictory information they may come across. They often present migration as highly desirable, where risks and failures in migration projects are downplayed and joked about, while benefits are glorified (compare Alpes, 2012).
This explains why members of the family often provide funds for migration projects.

The articles emphasize poverty, lack of perspectives, and network effects where a successful emigrant is often followed by others (Moyo, Nshimbi, \& Laine, 2020), but they distance themselves from almost mechanical perspectives where we can in principle calculate the probability of migration from objective (economic) factors. The articles are closer to the description of migrants as gamblers (Belloni, 2016), but emphasize a clear difference in that a gambler takes a known risk-the odds of winning are in principle known and fixed-whereas migrants make repeated decisions with limited, changing, and uncertain information. Drawing to some extent on two-step models differentiating ambitions to migrate from capabilities (Carling \& Schewel, 2018; de Haas, 2011), the articles demonstrate that two-step models do not adequately capture the repeated decisions under changing circumstances, experience, and information.

Second, formal and informal migration may be mixed on the 'journey,' as are periods of movement and temporary settlement. For many migrants, the circumstances on the way change, and they show enterprising flexibility to adjust to changing contexts: changing routes, teaming up with others, staying put for a while, or returning home. While most individuals interviewed in the context of these articles were well aware of the dangers of their journey-being defrauded, getting stuck, running out of money, severe violence or death-the hope for a better future and a mindset of solving challenges when they arrive imply that lack of information is not the main reason for irregular migration. Migration journeys are often not unidirectional but characterized by many decisions at each step of the journey (Bolay, 2014). The articles show that different narratives and information can influence the migration journey as individuals learn more about risks and likely outcomes as they progress, and as migrants adjust desired routes and channels of migration. Many articles identify strong hurdles against returning 'empty-handed,' even though there are narratives that blame bad luck or unfortunate spirits to 'save face' for individuals with 'failed' migration projects.

Third, with the increasingly difficult routes across the Mediterranean, some individuals formally sign up for studies in countries such as Northern Cyprus or Arab countries as an intermediate destination, mixing formal and informal migration (Dako-Gyeke, 2016; Piguet, Nassa, Ndiaye, Oumarou, \& Wade, 2020). Student migration may offer a credible alternative for individuals seeking a better life in Europe, but levels of information are often low and incomplete, meaning that potential students navigate in narratives rather than research their own information. At the same time, student migration serves well to highlight immobility: There are students who eschew their opportunity to spend time abroad, despite their stating an ambition to live abroad for some time and having the financial support from the universities-migration velleity rather than ambition. 
This counterfactual constitutes an important piece in understanding decision-making, as it helps us identify how different narratives play a role in actual migration decisions, and why ambitions and capabilities alone do not necessarily translate into migration.

\section{Conclusion}

In conclusion, the articles in this thematic issue offer an opportunity to better understand migration decisions under limited and contradictory information. It transpires that narratives are used as heuristics to make sense of the world sketched by bits and pieces of information, but also that complex decisions like migration should better be understood as a series of decisions all under great uncertainty. Seen this way, providing 'better' information is simplistic and does not do justice to the role of narratives as heuristics to navigate uncertainty, and the fact that some migrants are indeed well-informed and aware of the risks of migration. Narratives play an important role at each decision, which are embedded in particular contexts and social networks that spread and filter information. The articles in this thematic issue highlight that 'migrants' from Africa are far from a homogenous population (see also Crawley et al., 2016), and underscore the agency and flexibility of migrants in reaching goals.

\section{Acknowledgments}

This research was supported by the State Secretariat for Education, Research and Innovation (SERI), and the National Center of Competence in Research nccr-on the move funded by the Swiss National Science Foundation, under grant number 51NF40-182897.

\section{Conflict of Interests}

The author declares no conflict of interests.

\section{References}

Alpes, M. J. (2012). Bushfalling at all cost: The economy of migratory knowledge in Anglophone Cameroon. African Diaspora, 5(1), 90-115. https://doi.org/ 10.1163/187254612X646189

Auer, D., Römer, F., \& Tjaden, J. (2020). Corruption and the desire to leave quasi-experimental evidence on corruption as a driver of emigration intentions. IZA Journal of Development and Migration, 11(1). https://doi.org/10.2478/izajodm-2020-0007

Baláž, V., Williams, A. M., \& Fifeková, E. (2016). Migration decision making as complex choice: Eliciting decision weights under conditions of imperfect and complex information through experimental methods. Population, Space and Place, 22(1), 36-53.

Batista, C., \& McKenzie, D. (2020). Testing classic theories of migration in the lab. Paper presented at the Annual Migration Meeting, UCD Geary Institute for Public Policy, Ireland. Retrieved from https://research.unl.pt/ws/portalfiles/portal/ 26626231/batista_c2249.pdf

Belloni, M. (2016). Refugees as gamblers: Eritreans seeking to migrate through Italy. Journal of Immigrant \& Refugee Studies, 14(1), 104-119.

Bolay, M. (2014). When miners become "foreigners": Competing categorizations within gold mining spaces in Guinea. Resources Policy, 40, 117-127.

Carling, J., \& Schewel, K. (2018). Revisiting aspiration and ability in international migration. Journal of Ethnic and Migration Studies, 44(6), 945-963.

Collier, P. (2013). Exodus: How migration is changing our world. London: Allen Lane.

Constant, A. F., \& Zimmermann, K. F. (2013). International handbook on the economics of migration. Cheltenham: Edward Elgar Publishing.

Crawley, H., Jones, K., McMahon, S., Duvell, F., \& Sigona, N. (2016). Unpacking a rapidly changing scenario: Migration flows, routes and trajectories across the Mediterranean (Research Brief No.1). Coventry: MEDMIG. Retrieved from http://www.medmig.info/ wp-content/uploads/2016/03/MEDMIG-Briefing01-March-2016-FINAL-1.pdf

Dako-Gyeke, M. (2016). Exploring the migration intentions of Ghanaian youth: A qualitative study. Journal of International Migration and Integration, 17(3), 723-744.

de Haas, H. (2011). The determinants of international migration: Conceptualizing policy, origin and destination effects. IMI Working Papers, 32, 1-35.

Kahneman, D. (2011). Thinking, fast and slow. New York, NY: Farrar, Straus and Giroux.

Laurence, J., Schmid, K., \& Hewstone, M. (2018). Ethnic diversity, ethnic threat, and social cohesion: (Re)-evaluating the role of perceived out-group threat and prejudice in the relationship between community ethnic diversity and intra-community cohesion. Journal of Ethnic and Migration Studies, 45(3). https://doi.org/10.1080/1369183X.2018. 1490638

Moyo, I., Nshimbi, C. C., \& Laine, J. (2020). Migration conundrums, regional integration and development: Africa-Europe relations in a changing global order. London: Palgrave Macmillan.

Piguet, E., Nassa, D., Ndiaye, E. H. M., Oumarou, A., \& Wade, C. S. (2020). African students' emigration intentions: Case studies in Côte d'Ivoire, Niger, and Senegal. African Geographical Review. Advance online publication. https://doi.org/10.1080/ 19376812.2020.1848595

Ruedin, D., \& Nesturi, M. (2018). Choosing to migrate illegally: Evidence from return migrants. International Migration, 56(4), 235-249.

Smith, S. (2019). The scramble for Europe: Young Africa on its way to the old continent. Hoboken, NJ: Wiley. van der Brug, W., D’Amato, G., Berkhout, J., \& Ruedin, D. 


\section{COGITATIO}

(Eds.). (2015). The politicisation of migration. London and New York, NY: Routledge.

Zschirnt, E., \& Ruedin, D. (2016). Ethnic discrimination in hiring decisions: A meta-analysis of correspondence tests 1990-2015. Journal of Ethnic and Migration Studies, 42(7), 1115-1134.

\section{About the Author}

Didier Ruedin (DPhil, Oxford) is a Research Associate at the University of the Witwatersrand and a Senior Researcher at the University of Neuchâtel. He uses experiments and quantitative analysis to study social inequalities and reactions to them, especially in the field of immigration and ethnic minority groups. His research examines social inequalities through ethnic discrimination, politicization, public policies, and attitudes. Personal website: http://druedin.com 